\title{
Correspondence
}

\section{The cost of anaesthetic vapours}

To the Editor:

Increasingly, we find ourselves having to justify the cost of our anaesthetic drugs. Although it is easy to obtain the cost of a vial of fentanyl or propofol the cost of inhalation anaesthetics is more elusive. Herein is provided a formula to calculate these costs.

The cost in dollars is $\frac{\text { PFTMC }}{2412 \mathrm{~d}}$

where $\mathrm{M}, \mathrm{C}$, and $\mathrm{d}$ are agent specific and are defined:

\begin{tabular}{lcccc}
\hline & & Halothane & Enflurane & Isoflurane \\
\hline Molecular weight $(\mathrm{g})$ & $\mathrm{M}$ & 197.4 & 184.4 & 184.4 \\
Cost $\left(\$ \cdot \mathrm{ml}^{-1}\right)$ & $\mathrm{C}$ & 0.069 & 0.5 & 0.86 \\
Density $\left(\mathrm{g} \cdot \mathrm{ml}^{-1}\right)$ & $\mathrm{d}$ & 1.87 & 1.52 & 1.50 \\
\hline
\end{tabular}

The three other variables are the vaporizer concentration, (\%) P, the fresh gas flow, $\mathrm{F}\left(\mathrm{L} \cdot \mathrm{min}^{-1}\right)$, and the duration of anaesthesia, $\mathrm{T}(\mathrm{min})$. The formula can be simplified to:

$$
\begin{aligned}
\text { Cost }(\$) & =\mathrm{PFT} / 331 \text { for halothane at } \$ 17.25 / 200 \mathrm{ml} \\
& =\mathrm{PFT} / 39 \text { for enflurane at } \$ 126.00 / 250 \mathrm{ml} \\
& =\mathrm{PFT} / 23 \text { for isoflurane at } \$ 86.00 / 100 \mathrm{ml}
\end{aligned}
$$

Example: a $45 \mathrm{~min}$ anaesthetic, with $0.75 \%$ enflurane and oxygen and nitrous oxide at 2 and $4 \mathrm{~L} \cdot \mathrm{min}^{-1}$ costs $0.75 \times 6 \times 45 / 39-\$ 5.19$.

This calculation assumes the gases are delivered from the machine at an atmospheric density corresponding to $21^{\circ} \mathrm{C}$ and explains the factor 2412 in the formula. At $0^{\circ} \mathrm{C}$, the number 2240 would be used, corresponding to the molar volume of a gas of $22.4 \mathrm{~L}$.

Peter Dion MD PhD FRCPC

St. Catharines General Hospital Ontario.

\section{Spinal catheter does not reduce post-dural puncture headache after Caesarean section}

To the Editor:

The purpose of the following study was to determine whether the incidence of PDPH after Caesarean section could be reduced by keeping a $28 \mathrm{G}$ spinal catheter in place for $24 \mathrm{hr}$. In 32 patients a 22G needle (Quincke, BecktonDickicson) was introduced between the $L_{3}-L_{4}$ or $L_{4}-L_{5}$ vertebrae. A 28G spinal polyurethane catheter (Preferred Medical Products, Toronto, Canada) was introduced two to three $\mathrm{cm}$ into the subarachnoid space through the needle, after which the needle was removed and local anaesthetics were injected in increasing amounts to reach a sufficient level of anaesthesia. The patients were randomly assigned to have the catheter removed immediately after surgery (Group 1), or $24 \mathrm{hr}$ later (Group 2). The measured variables are reported in the Table. Statistical analyses were done using the Student $t$ test and the ANOVA for parametric data and the Chi-Square test and Mann Whitney test were used for the non-parametric values. Statistical significance was defined at a $P \leq 0.05$.

Twenty four hr catheterization of the subarachnoid space did not reduce the incidence of headache associated with spinal anaesthesia in pregnant patients. Our data do not confirm previous data and do not support the hypothesis that the local inflammatory reaction of the dura caused by the catheter, with oedema and fibrinous exudate, will seal the hole when the catheter is removed. ${ }^{1}$ If spinal catheters produce inflammation in humans as they do in

TABLE

\begin{tabular}{lll}
\hline & $\begin{array}{l}\text { Group 1 } \\
\text { No. 17 catheter } \\
\text { removed directly } \\
\text { afier surgery }\end{array}$ & $\begin{array}{l}\text { Group 2 } \\
\text { No. 15 catheter } \\
\text { removed } \\
24 \text { hr later }\end{array}$ \\
\hline Mean age & $29 \pm 0.8$ & $32 \pm 1.4$ \\
Mean weight (kg) & $76 \pm 5.5$ & $79 \pm 7.7$ \\
Total anaesthetic (ml) & $1.9 \pm 0.5$ & $2.3 \pm 0.2$ \\
Patient with previous c/s & $17(65 \%)$ & $12 / 15(80 \%)$ \\
$\begin{array}{l}\text { Post-spinal headache } \\
\text { Mean duration of }\end{array}$ & $6 / 17(35.2 \%)$ & $6 / 15(40 \%)$ \\
$\quad$ PDPH (hr) & $46 \pm 7$ & $57 \pm 9$ \\
Blood patch & & 3 \\
\hline (no. of patients) & 5 & \\
\hline
\end{tabular}


animals, ${ }^{2}$ the longer the catheter is in place the larger the inflammatory reaction will be. As we did not find a difference, we must conclude either that the inflammatory response to the catheter does not exist, that it is reduced in pregnancy, or that the local inflammation cannot reduce post-spinal headache. It is not known if the material from which the catheter is made (polyurethane versus nylon) influences the inflammatory response. It is possible that in our study the hole in the dura made by a $22 \mathrm{G}$ needle was too large for the diameter of the $28 \mathrm{G}$ catheter and facilitates the amount of CSF lost and increases PDPH.

Norris and Leighton also did not find a beneficial effect of subdural catheterization to treat PDPH. ${ }^{3}$ Their data and ours confirm that subdural catheterization neither prevents nor treats PDPH after delivery.

\section{REFERENCES}

1 Denny N, Masters R, Pearson D, Read J, Sihota M, Selan$\operatorname{der} D$. Postdural puncture headache after continuous spinal anesthesia. Anesth Analg 1987; 66: 791-4.

2 Yaksh TL, Nouihed RY, Durant PAC. Studies of the pharmacology and pathology of intrathecally administered 4anilinopiperidine analogues and morphine in the rat and cat. Anaesthesiology 1986; 64: 54-66.

3 Norris $M C$, Leighton $B L$. Continuous spinal anaesthesia after unintentional dural puncture in parturients. Regional Anaesthesia 1990; 15: 285-7.

\author{
G.A. Blaise MD \\ S. Cournoyer RN \\ C. Perrault MD \\ M.-J. Bédard MD \\ F. Petit MD \\ Daniel Landry MD \\ Departments of Anaesthesia \\ Nursing and Gynecology \\ Notre-Dame Hospital and University of Montreal \\ Montreal, Quebec, Canada H2L 4M1
}

\section{Erratum}

Re: Concentration of fentanyl in colostrum after an analgesic dose. P.L. Steer, C.J. Biddle, W.S. Marley, R.K. Lantz, P.L. Sulik. Can J Anaesth 1992; 39: 231-5.

\section{Results}

Radioimmunoassay showed that fentanyl appeared in colostrum. The highest concentration, at the times measured, was $0.40 \pm 0.059 \mathrm{mg} \cdot \mathrm{ml}^{-1} 45 \mathrm{~min}$ after intra-

Please note that 3rd line should read:

measured, was $0.40 \pm 0.059 \mathrm{ng} \cdot \mathrm{ml}^{-1} 45 \mathrm{~min}$ after intra- 